PREPARED FOR THE U.S. DEPARTMENT OF ENERGY, UNDER CONTRACT DE-AC02-76CH03073

PPPL-3710

PPPL-3710

UC-70

Physics Analysis of the FIRE Experiment

by

S.C. Jardin, C.E. Kessel, D. Meade, J. Breslau, G. Fu,

N. Gorelenkov, J. Manickam, W. Park, and H. Strauss

June 2002

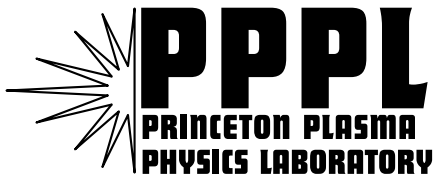

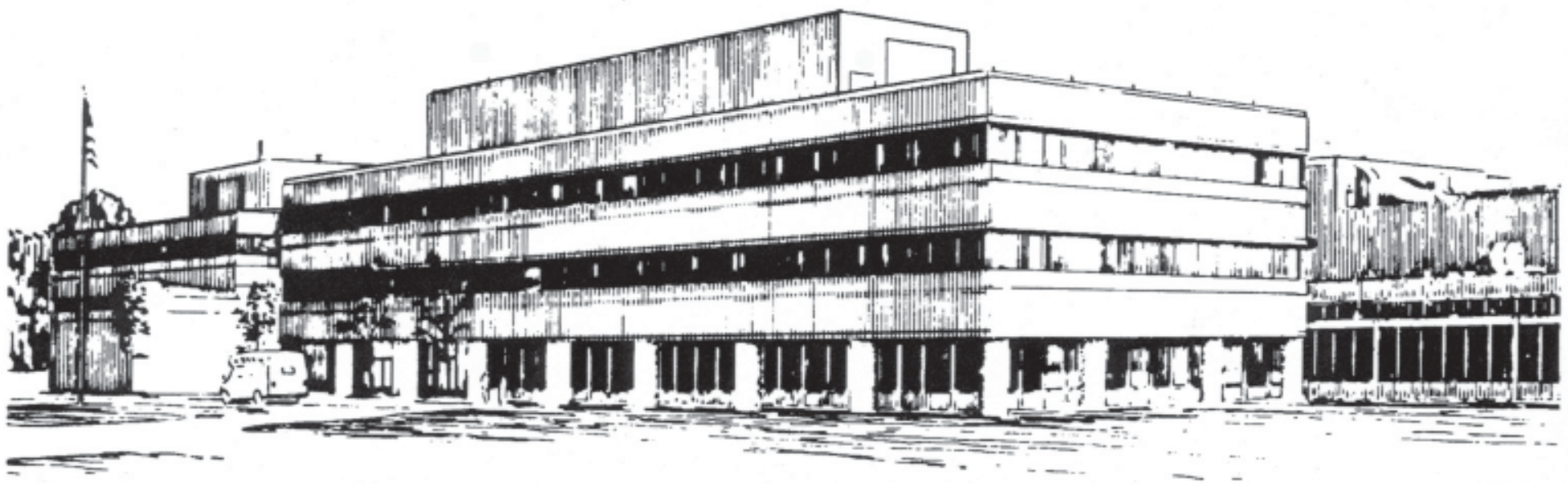

PRINCETON PLASMA PHYSICS LABORATORY PRINCETON UNIVERSITY, PRINCETON, NEW JERSEY 


\section{PPPL Reports Disclaimer}

This report was prepared as an account of work sponsored by an agency of the United States Government. Neither the United States Government nor any agency thereof, nor any of their employees, makes any warranty, express or implied, or assumes any legal liability or responsibility for the accuracy, completeness, or usefulness of any information, apparatus, product, or process disclosed, or represents that its use would not infringe privately owned rights. Reference herein to any specific commercial product, process, or service by trade name, trademark, manufacturer, or otherwise, does not necessarily constitute or imply its endorsement, recommendation, or favoring by the United States Government or any agency thereof. The views and opinions of authors expressed herein do not necessarily state or reflect those of the United States Government or any agency thereof.

\section{Availability}

This report is posted on the U.S. Department of Energy's Princeton Plasma Physics Laboratory Publications and Reports web site in Fiscal Year 2002. The home page for PPPL Reports and Publications is: http://www.pppl.gov/pub_report/

DOE and DOE Contractors can obtain copies of this report from:

U.S. Department of Energy

Office of Scientific and Technical Information

DOE Technical Information Services (DTIS)

P.O. Box 62

Oak Ridge, TN 37831

Telephone: (865) 576-8401

Fax: (865) 576-5728

Email: reports@adonis.osti.gov

This report is available to the general public from:

National Technical Information Service

U.S. Department of Commerce

5285 Port Royal Road

Springfield, VA 22161

Telephone: 1-800-553-6847 or

(703) 605-6000

Fax: (703) 321-8547

Internet: http://www.ntis.gov/ordering.htm 


\title{
Physics Analysis of the FIRE experiment
}

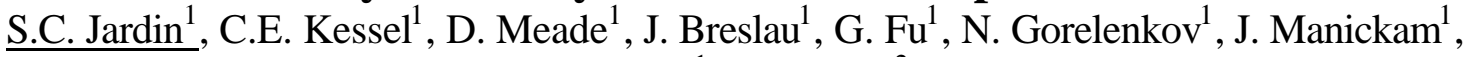 \\ W. Park ${ }^{1}$, H. Strauss ${ }^{2}$ \\ ${ }^{1}$ Princeton Plasma Physics Laboratory, Princeton NJ 08540 USA \\ ${ }^{2}$ Courant Institute of Mathematical Science, New York University, New York, NY
}

\begin{abstract}
An integrated model of a complete discharge in the FIRE experiment has been developed based on the TSC simulation code. The complete simulation model includes a choice of several models for core transport, combined with an edge pedestal model and the Porcelli sawtooth model. Burn control is provided by feedback on the auxiliary heating power. We find that with the GLF23 and MMM95 transport models, Q >10 operation should be possible for H-mode pedestal temperatures in the range of $4-5 \mathrm{keV}$.
\end{abstract}

\section{Introduction:}

The proposed Fusion Ignition Research Experiment (FIRE) is a \$1B class facility that will be capable of exploring many of the burning plasma physics issues of interest to our community. The device dimensions can be "derived" from an optimization algorithm where we seek the most compact configuration that utilizes wedged copper alloy toroidal field coils pre-cooled to $80^{\circ} \mathrm{K}$ and without active cooling [1]. The constraints imposed during the optimization include ELMy $\mathrm{H}$-mode ITER98(y,2) scaling for the energy confinement time, a density limit of $\mathrm{n}_{20}<0.75 \mathrm{n}_{\mathrm{GW}}$, sufficient power to exceed the $\mathrm{H}$-mode power threshold, a normalized stability parameter of $\beta_{\mathrm{N}}<$ 1.8 , and a pulse length exceeding (by a factor of 2 ) that required for the plasma current profile to fully equilibrate to a stationary state. This leads to a reference design with $\mathrm{R}_{0}=2.14 \mathrm{~m}, \mathrm{a}=$ $0.595 \mathrm{~m}, \mathrm{~B}_{\mathrm{t}}\left(\mathrm{R}_{0}\right)=10 \mathrm{~T}, \mathrm{I}_{\mathrm{P}}=7.7 \mathrm{MA}$ with a flattop time at full parameters of $20 \mathrm{~s}$, and with150 MW of fusion power. The strong shaping $\left(\delta_{\mathrm{X}}=0.7, \kappa_{\mathrm{X}}=2.0\right)$ and low normalized density can be expected to improve the confinement to a multiplier of 1.1 applied to the H98 $(y, 2)$ global confinement time scaling, projecting to a fusion gain $\mathrm{Q} \sim 10$ [2].

\section{Core Transport and Boundary Conditions:}

There are several transport models that have been developed for use in predicting the profiles and performance in a burning plasma. We have implemented three of the leading models in the TSC integrated modeling code [3] and used them to predict the performance of FIRE and the type of MHD behavior to expect. The three models are (A) the Multi-Mode Model MMM95 [4], (B) the Gyro-Landau Fluid model GLF23 [5], and (C) the "standard TSC" Coppi-Tang model [3]. These models are supplemented by a sawtooth model and boundary and edge models.

The H-mode models (A) and (B) are only applied in the central region $0<\Phi<0.75$, where $\Phi$ is the normalized toroidal magnetic flux that is zero at the magnetic axis and unity at the plasma/vacuum separatrix. In the edge region $0.75<\Phi<1.0$, we use an edge transport model $\chi_{\mathrm{i}}$ $=\chi_{\mathrm{e}}=\mathrm{C} / \mathrm{n}_{\mathrm{e}}$, where $\mathrm{n}_{\mathrm{e}}$ is the local electron density and $\mathrm{C}$ is a constant chosen as $\mathrm{C}=2 \times 10^{19}$. The constant $\mathrm{C}$ has been chosen to make the pressure gradient in this region just below the infinite- $\mathrm{n}$ ballooning mode stability criteria. This leads to electron and ion temperatures at the top of the 
pedestal, $\Phi=0.75$, of $4-5 \mathrm{KeV}$. For transport model (C), we impose a separatrix temperature at $\Phi=1.00$ of $\mathrm{Te}=\mathrm{T}_{\mathrm{i}}=400 \mathrm{eV}$.

The density profile is not advanced in time in these simulations, but is rather a prescribed function of normalized poloidal flux, $\psi$, and time, t. We take the electron density to be $\mathrm{n}_{\mathrm{e}}(\psi, \mathrm{t})=$ $\mathrm{n}_{0}(\mathrm{t}) \times\left[\left(1 .-\psi^{\beta}\right)^{\alpha}+\mathrm{r}_{\text {edge }}\right]$, with $\alpha=0.3, \beta=2.25, \mathrm{n}_{0}=5.8 \times 10^{19}$ and $\mathrm{r}_{\text {edge }}=0.3$ during the current flattop. This leads to a line-averaged density of 0.60 times the Greenwald limit, and a ratio of peak to volume average of 1.15 . We also include a uniform distribution of $3 \%$ Beryllium impurity, which together with the He buildup (assuming $\tau_{\mathrm{P}}=5 \mathrm{sec}$ ), leads to a value of $\mathrm{Z}_{\mathrm{EFF}} \sim$ 1.4 during the flattop.

\section{Sawtooth Model:}

One of the major uncertainties in the physics design of a burning plasma experiment is the behavior of the internal $m=1$ mode. We have implemented the Porcelli sawtooth model [6] in TSC and have investigated its consequences on transport and ignition. The nonlinear M3D code has been used to investigate the assumptions made in the Porcelli model and to evaluate the consequences of the sawtooth crash in FIRE-like devices, including the effects on the highenergy Helium population and the formation of stochastic regions outside the $q=1$ surface. In the present integrated modeling simulations, we assume that the surfaces outside the inversion surface remain good during the sawtooth activity.

The Porcelli sawtooth model triggers an event if one of the following 3 criteria is met:

$$
\begin{gathered}
-\delta \hat{W}_{\text {core }}>\omega_{D h} \tau_{A} \\
-\delta \hat{W}>0.5 \omega_{* i} \tau_{A} \\
\hat{\rho}<-\delta \hat{W}<0.5 \omega_{*_{i}} \tau_{A} \text { and } \omega_{*_{i}}<\gamma_{\rho}
\end{gathered}
$$

Here, $\delta \hat{W}=\delta \hat{W}_{\text {core }}+\delta \hat{W}_{\text {fast }}$, where $\delta \hat{W}_{\text {core }}=\delta \hat{W}_{\text {mhd }}+\delta \hat{W}_{K O}$. We have used the approximations in Ref. [6] for the various terms but have modified the coefficients by comparing them with the more exact results obtained by PEST and NOVA-K. We find that the Porcelli expression for $\delta \hat{W}_{\text {fast }}$ needs to be multiplied by $\sqrt{ } 2$ to get agreement with NOVA-K for this geometry. The PEST calculations shows the importance of calculating the $\delta \hat{W}_{m h d}$ with the correct wall boundary condition, consistent with [8]. When the sawtooth is predicted to be triggered, we modify the transport coefficients in two ways. The value of the toroidal flux at the inversion surface, $\Phi_{1}$, is calculated as $\int_{0}^{\Phi_{1}}\left(\frac{1}{q(\Phi)}-1\right) d \Phi=0$

For the duration of the sawtooth crash time $\tau_{\mathrm{CRASH}}$, we define the thermal conductivity and the hyper-resistivity to be: $\chi=\mathrm{r}_{1}{ }^{2} / \tau_{\mathrm{CRASH}}$ and $\lambda=\lambda_{0} \mathrm{~B}_{0}{ }^{2} \mathrm{r}_{1}{ }^{4} / \tau_{\mathrm{CRASH}}$. A value of $\lambda_{0}=0.1$ effectively causes a Kadomtsev reconnection to occur [7] in the time $\mathrm{t}=\tau_{\mathrm{CRASH}}$, which we took to be $10 \mathrm{~ms}$ in these runs. By lowering $\lambda_{0}$ to 0.001 , we can model an incomplete reconnection where the temperature profile flattens but the current and flux do not fully reconnect. 
$\begin{array}{lll}\text { (A) MMM95 } & \text { (B) GLF23 } & \text { (C) Coppi-Tang }\end{array}$

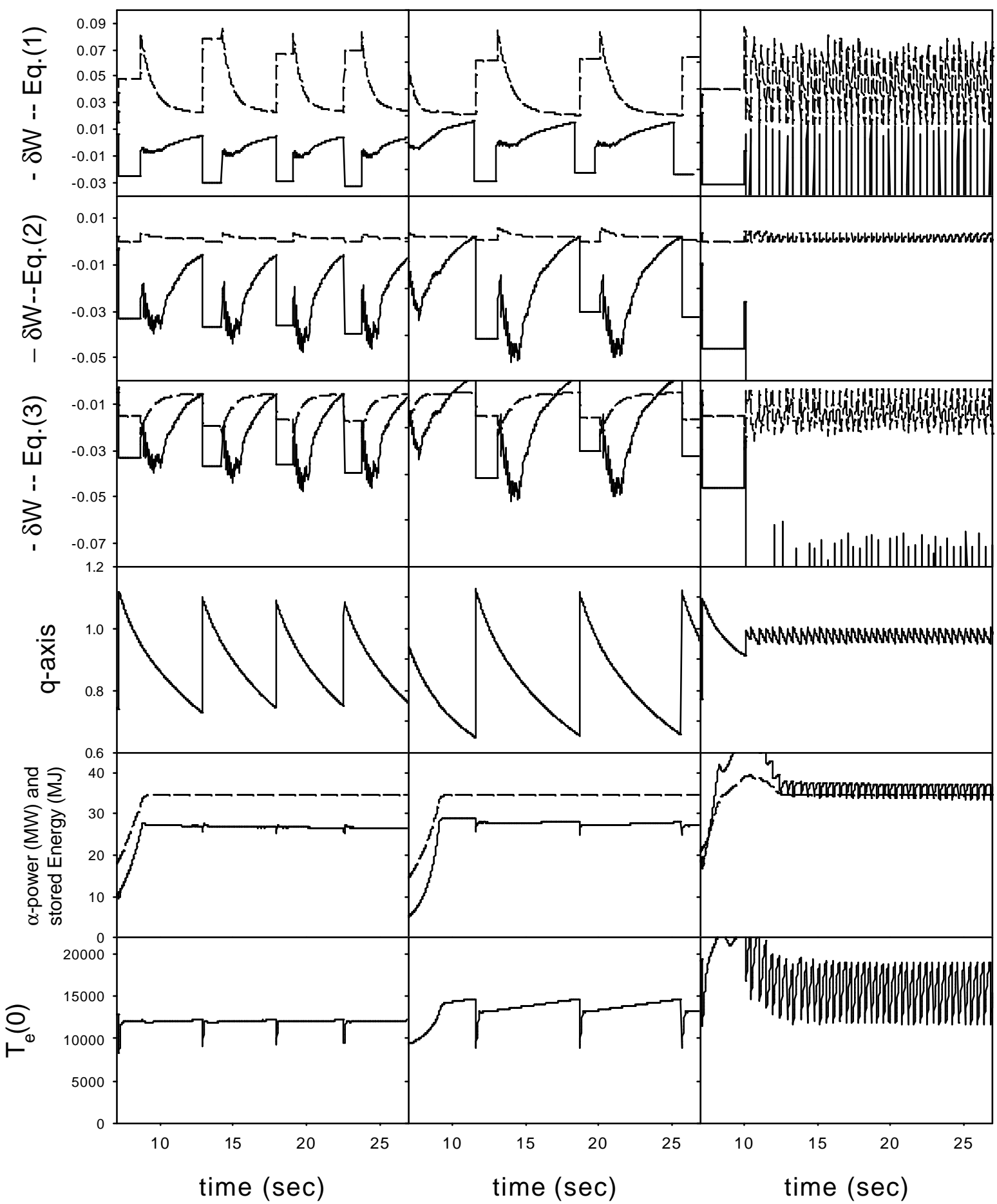

Figure 1: Results of the complete reconnection Porcelli sawtooth model. The top three frames show the appropriate $-\delta \mathrm{W}$ from the Porcelli model (solid) and the critical value (dashed) for the 3 transport models for the 3 criteria corresponding to Eqns. (1)-(3). During the flattop, for the simulation using model (A), the sawtooth is triggered by criteria 3 , for model (B) it is criteria 2 , and for model (C) it is criteria 1 . The $4^{\text {th }}$ row shows the safety factor on axis for each of the 3 models. The final rows show the total stored energy $(W)$ and the instantaneous $\alpha$-power, and central electron temperature Te(0). 

(A) MMM95
(B) GLF23
(C) Coppi-Tang

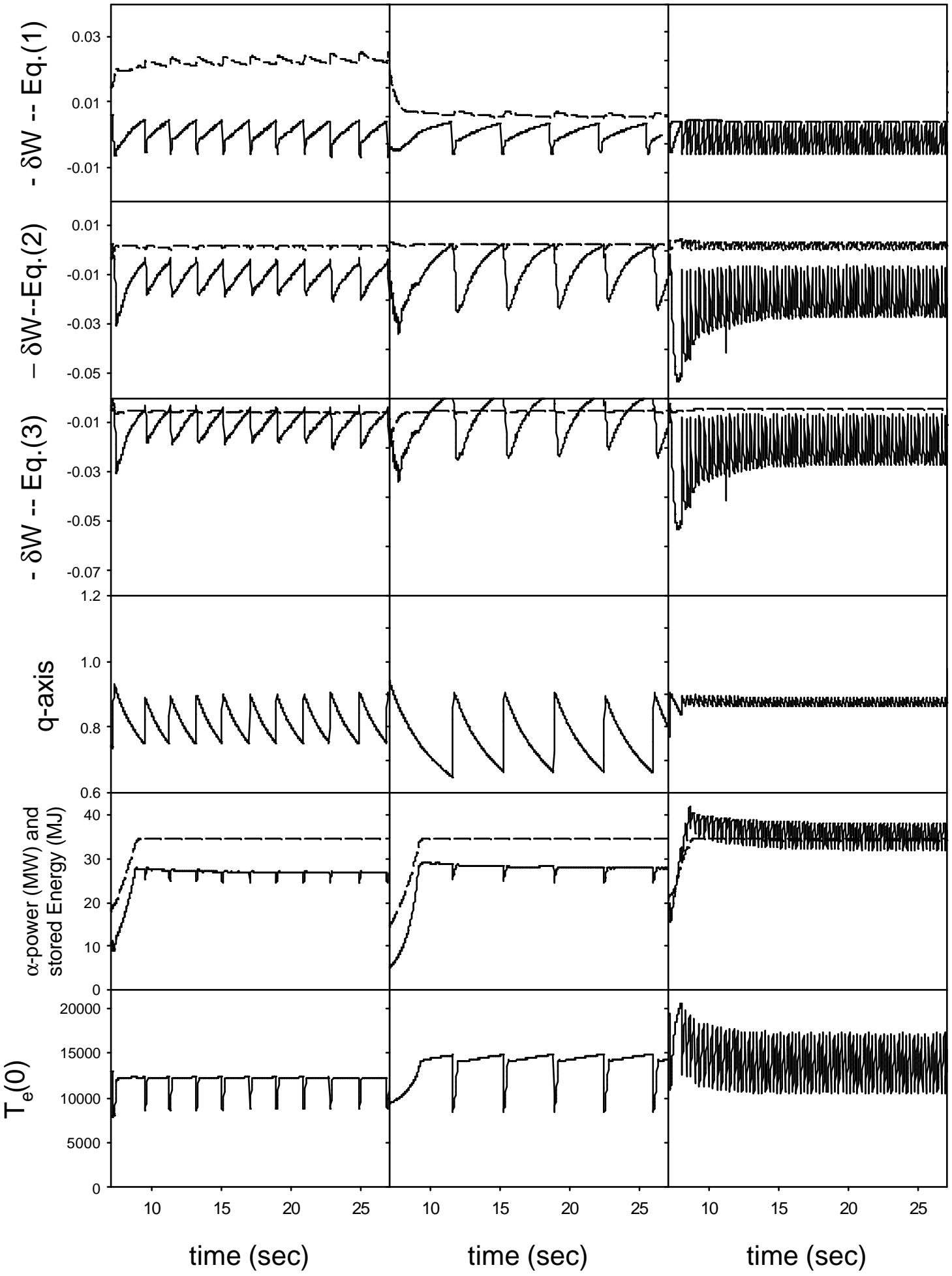

Figure 2: Same as Figure 1, but for a incomplete reconnection model. 


\section{Discharge Simulation:}

We have developed a full 1 1/2D TSC integrated simulation of a complete FIRE discharge including current rampup, flattop, burn, and current rampdown for each of the three transport models, and utilizing the Porcelli sawtooth model. We utilize a feedback system on the ICRH power designed to keep the total stored energy W constant at $34.5 \mathrm{MJ}$ of total stored energy. Each of these simulations results in an energy multiplication factor $Q>10$. Selected results are presented in Figures 1, 2 and 3. Each of these three models leads to a different behavior of the sawtooth as shown in these figures. As seen in Figure 1, for the complete sawtooth reconnection, the model $\mathrm{A}$ (MMM95) has sawteeth every $\sim 5$ seconds triggered by the criteria in Eq. (3), the model B (GLF23) has sawteeth every $~ 7$ seconds, triggered by the criteria in Eq. (2). In model C (Coppi-Tang), the sawteeth occur much more frequently, about every 0.5 -second, and are triggered by the criteria in Eq. (1). The electron temperature and safety factor profiles just before and after the last crash for these runs are shown in Figure 3. The instantaneous alpha power production and total stored energy are staying relatively constant in each of these runs, as shown in the bottom row of Figure 1. When these runs are repeated but using the incomplete reconnection model $\left(\lambda_{0}=0.001\right)$, we find very similar results (see Figure 2$)$, with the primary difference being that the sawtooth frequency increases ( $2 \mathrm{sec}, 3.5 \mathrm{sec}, 0.2 \mathrm{sec})$ and the excursion in $\mathrm{q}_{0}$ is less $[(.75, .90),(.67,90),(.86, .89)]$, but the performance and $\mathrm{Q}$ value are essentially unchanged.

Figure 3: Electron temperature and safety-factor profiles just before (solid) and after (dotted) a sawtooth crash the (A) MMM95, (B) GLF23, (C) Coppi-Tang transport simulations with a complete reconnection.

\section{Advanced Mode Operation:}

Besides the reference inductive high-performance operating mode, the FIRE device is capable of operating at reduced parameters for longer times. The addition of a 20 MW LHCD system at 5.6 $\mathrm{GHz}$ will enable long pulse operation at reduced fields. Advanced tokamak configurations without relying on wall stabilization have been

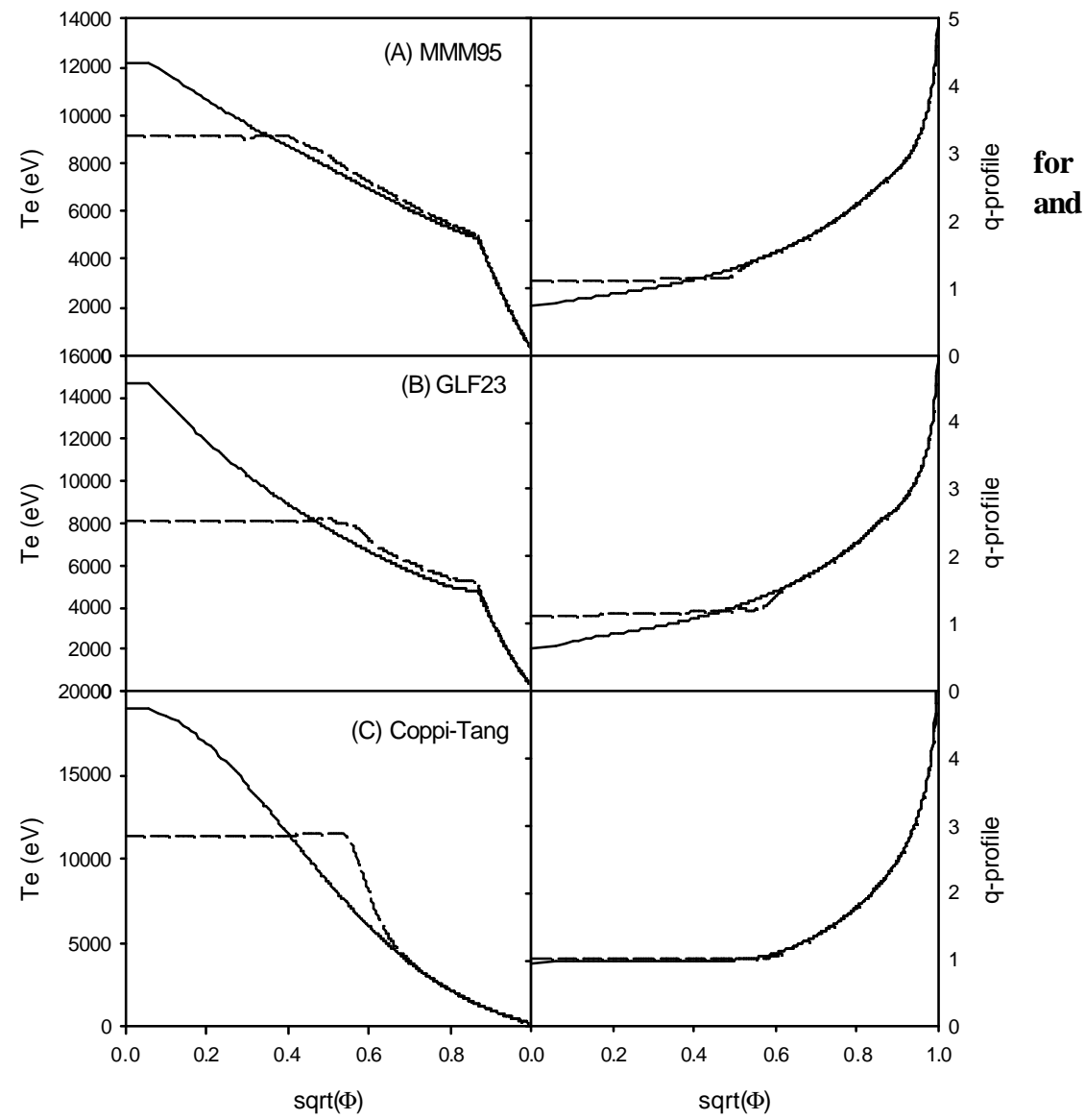

modeled with $\beta_{N}=2.5$. We have used TSC/LSC to simulate a fully non-inductive discharge at a 
bootstrap fraction of up to $70 \%$ with a wall-stabilized $\beta_{N}=3.5$ at fusion gain $Q>5$. A close fitting copper-clad passive stabilizer provides $n=0$ and $n=1$ mode control.

Acknowledgements: The authors have benefited from discussions with G. Bateman, J. Kinsey, and A. Kritz. The MMM95 and GLF23 subroutines were downloaded from the NTCC modules library [http://w3.pppl.gov/NTCC]. This work was supported by DOE Contract \# DE- AC02$76 \mathrm{CHO} 3073$.

\section{REFERENCES}

[1] Jardin SC; Kessel C; Meade D; Neumeyer C; PPPL-3666 (to appear in Fus Eng and Des)

[2] J.G. Cordey, et al., Proc. $28^{\text {th }}$ EPS Conf. On Con. Fus. And Plas Phys., 2001, paper 3.11

[3] Jardin SC; Bell MG; Pomphrey N; Nucl Fusion 33 (1993) 371

[4] Bateman, G; Kritz AH; Kinsey JE; Redd AJ, Physics of Plasmas 5 (1998) 2355

[5] Waltz R; et al, Phys. Plasmas 4 (1997) 1499

[6] Porcelli F; Boucher D; Rosenbluth M; Plas. Phys. and Cont. Fusion 38 (1996) 2163

[7] Ward DJ and Jardin SC Nucl Fusion 29 (1989) 905

[8] Lutjens H; Bondeson A; Vlad G; Nucl Fusion 32 (1992) 1625 


\section{External Distribution}

Plasma Research Laboratory, Australian National University, Australia

Professor I.R. J ones, Flinders University, Australia

Professor J oão Canalle, Instituto de Fisica DEQ/IF - UERJ , Brazil

Mr. Gerson O. Ludwig, Instituto Nacional de Pesquisas, Brazil

Dr. P.H. Sakanaka, Instituto Fisica, Brazil

The Librarian, Culham Laboratory, England

Library, R61, Rutherford Appleton Laboratory, England

Mrs. S.A. Hutchinson, JET Library, England

Professor M.N. Bussac, Ecole Polytechnique, France

Librarian, Max-Planck-Institut für Plasmaphysik, Germany

J olan Moldvai, Reports Library, MTA KFKI-ATKI, Hungary

Dr. P. Kaw, Institute for Plasma Research, India

Ms. P.J . Pathak, Librarian, Insitute for Plasma Research, India

Ms. Clelia De Palo, Associazione EURATOM-ENEA, I taly

Dr. G. Grosso, Instituto di Fisica del Plasma, Italy

Librarian, Naka Fusion Research Establishment, J AERI, J apan

Library, Plasma Physics Laboratory, Kyoto University, J apan

Research Information Center, National Institute for Fusion Science, J apan

Dr. O. Mitarai, Kyushu Tokai University, J apan

Library, Academia Sinica, Institute of Plasma Physics, People's Republic of China

Shih-Tung Tsai, Institute of Physics, Chinese Academy of Sciences, People's Republic of China

Dr. S. Mirnov, TRINITI, Troitsk, Russian Federation, Russia

Dr. V.S. Strelkov, Kurchatov Institute, Russian Federation, Russia

Professor Peter Lukac, Katedra Fyziky Plazmy MFF UK, Mlynska dolina F-2, Komenskeho Univerzita, SK-842 15 Bratislava, Slovakia

Dr. G.S. Lee, Korea Basic Science Institute, South Korea

Mr. Dennis Bruggink, Fusion Library, University of Wisconsin, USA

Institute for Plasma Research, University of Maryland, USA

Librarian, Fusion Energy Division, Oak Ridge National Laboratory, USA

Librarian, Institute of Fusion Studies, University of Texas, USA

Librarian, Magnetic Fusion Program, Lawrence Livermore National Laboratory, USA

Library, General Atomics, USA

Plasma Physics Group, Fusion Energy Research Program, University of California at San Diego, USA

Plasma Physics Library, Columbia University, USA

Alkesh Punjabi, Center for Fusion Research and Training, Hampton University, USA

Dr. W.M. Stacey, Fusion Research Center, Georgia Institute of Technology, USA

Dr. J ohn Willis, U.S. Department of Energy, Office of Fusion Energy Sciences, USA

Mr. Paul H. Wright, Indianapolis, Indiana, USA 
The Princeton Plasma Physics Laboratory is operated by Princeton University under contract with the U.S. Department of Energy.

\author{
Information Services \\ Princeton Plasma Physics Laboratory \\ P.O. Box 451 \\ Princeton, NJ 08543
}

Phone: 609-243-2750

Fax: 609-243-2751

e-mail: pppl_info@pppl.gov

Internet Address: http://www.pppl.gov 